\title{
Estimation of primary production of the waters around rack oyster farm at Wando, Korea
}

\author{
Woo-Geon Jeong ${ }^{1}$ and Sang-Man $\mathrm{Cho}^{2^{*}}$ (D)
}

\begin{abstract}
To establish a comprehensive management strategy, as part of the optimization of cultural practice for an oyster rack culture system, we used a numerical model to estimate the primary production in the waters on the eastern coast of Wando island, South Korea. The estimated primary production ranged from 17.12 to $1052.55 \mathrm{mgC} \mathrm{m}^{-2}$ day $^{-1}$ (204.22 $\pm 224.75 \mathrm{mgC} \mathrm{m}^{-2}$ day $^{-1}$ in average). Except for the times of peak phytoplankton blooms, the estimated primary production (PP) was consistently under $200 \mathrm{mgC} \mathrm{m}^{-2}$ day $^{-1}$, which is more similar to the value of PP measured off the western coast of South Korea than the southern coast. No clear relationship was observed between nitrogen content and rainfall with the exception of heavy rainfall events, indicating that precipitation might not be the main source of nutrients in these waters. No clear influence was observed from Doam tidal discharge, located $24 \mathrm{~km}$ north from these waters due to main tide comes in this area from the channel between Gunwe-myeon in Wando island and Pukpyeong-myeon in Haenam-gun. Because of the shallow water depth and strong tidal current, resuspension of sediments, which causes an input of nitrogen into the system, could be easily caused by even mild wind and the infrequent passing of ships. Microscopic examination of the phytoplankton composition showed additional contribution of benthic species such as Paralia sulcata into the waters, which increase the productivity of oyster farms in the waters. The availability of nitrate and phosphate for primary production was temporarily limited throughout most of the spring and autumn blooming season.
\end{abstract}

Keywords: Pacific oyster, Primary production, Oyster rack culture, Wando

\section{Background}

Oysters are suspension feeders that graze phytoplankton in the surrounding water column. This feeding behavior is facilitated by the cilia located on the gill filaments. These filaments generate water currents over the gills, select for food particles from the water column, transport food particles towards the mouth, and reject pseudofeces onto the mantle (Newell and Langdon 1996). Since the velocity field for feed behavior is highly restricted within organism's microenvironment (Uslu and Pekkan 2016), primary production could be a key factor in determining the productivity of oyster farms.

The present study site is located on the tidal flat of the eastern coast of Wando, which is positioned in narrow

\footnotetext{
* Correspondence: gigas@kunsan.ac.kr

${ }^{2}$ School of Applied Marine bioscience, Kunsan National University, Gunsan 573-701, Korea

Full list of author information is available at the end of the article
}

waterway between Wando and Gogeum Island. This area was previously well known for Porphyra aquaculture. Annual production in this region accounted for $\sim 22 \%$ of national production in South Korea; however, an environmental change linked to changing demographic and industrial development means that Porphyra aquaculture has ceased in the tidal flats in Wando (Lee 2006; Han and Cho 2013). As an alternative fishery in the tidal flats, oyster rack culturing was introduced as a pilot project in 2013 (Cho et al. 2013a). Here, we optimized several conditions to achieve the maximum sustainable yield (MSY) in these oyster rack cultures (Han and Cho 2013).

To ensure the successful management of oyster culture, many factors must be considered, but primary production is one of the most vital to achieving the MSY. Since oysters are filter feeders that rely solely on the surrounding environment as an energy source, an accurate estimation of primary production (PP) is 
essential to evaluate the potential yields in oyster farm (Lee et al. 1991). In this study, we estimate the PP to optimize the cultural practices (e.g., cultural density, nursery technique) that can yield crucial information on the best practices for managing an oyster farm.

\section{Methods}

\section{Seawater analysis}

Seawater was sampled monthly at the surface of five sampling sites from June 2011 to December 2012 (Fig. 1) using a Niskin sampler. Water temperature, salinity, and dissolved oxygen (DO) were measured by multiprobe system (YSI 556, YSI, Ohio, USA). Chlorophyll-a content was determined as described by Parson et al. (1984) after filtration of seawater using GF/C filter. Dissolved inorganic nitrogen (DIN) and dissolved inorganic phosphorus (DIP) were determined followed by Korean standard method for marine environment (Fisheries 2013).

\section{Estimation of primary production}

To estimate primary production, a numerical model was developed to predict photosynthetic rate from water temperature, solar irradiation, and chlorophyll-a content (Jeong et al. 2009). The model is briefly described below.

\section{Solar irradiance and attenuation coefficient ( $k$ )}

Solar irradiance at the sea surface was determined using an LI-1000 datalogger equipped with an LI-190SA quantum sensor (LI-COR, Nebraska, USA; $\mathrm{mol} \mathrm{m}^{-2} \mathrm{~s}^{-1}$ ), which was situated on the roof of our laboratory. Depthdependent variations of irradiance in the water column were determined using an LI-193SA spherical underwater quantum sensor (LI-COR, USA). The data were normalized with the exponential attenuation phase. The irradiance at a given depth in the water column $\left(C_{\mathrm{z}}\right)$ is estimated by Eq. (1) as follows:

$$
C_{\mathrm{Z}}=C_{0} \times e^{-k \cdot Z}
$$

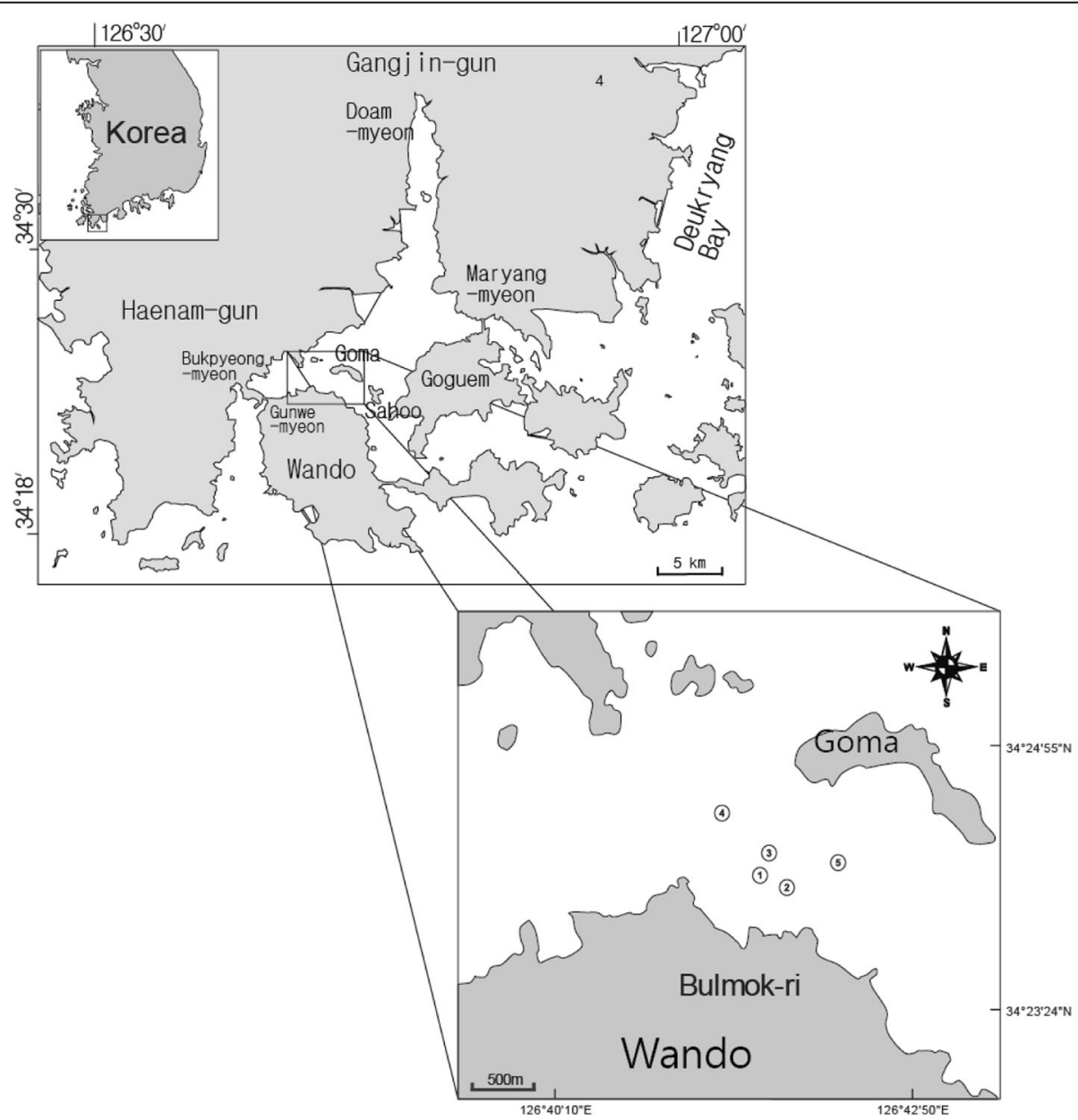

Fig. 1 Map showing the location of the study site, including the five stations off Bulmok-ri Port on Wando island where water samples were collected to study water quality and primary production 
where $C_{0}, k$, and $Z$ are irradiance at the surface, attenuation coefficient, and depth $(\mathrm{m})$, respectively. In the study, the total water column was considered as a euphotic zone to be included in the estimation of primary production because of the shallow depth not over the $3 \mathrm{~m}$ even at full tide.

\section{Relationship between irradiation, water temperature, and photosynthesis}

Primary production was estimated following Steemann Nielsen (1975) using a hyperbolic function between irradiation and photosynthetic rate, which was saturated from $20.6 \times 10^{15}$ to $90 \times 10^{15}$ quanta $\mathrm{cm}^{-2} \mathrm{~s}^{-1}$ at $20{ }^{\circ} \mathrm{C}$. The saturation point of the hyperbolic relationship increases with increasing water temperature (Steemann Nielsen 1975). Here, the relationship was modified to a biquadratic model between water temperature and saturated irradiation.

\section{Daily primary production}

To estimate the primary production, irradiance data must be normalized to $20^{\circ} \mathrm{C}$. If irradiance at depth $z\left(Q_{z}\right)$ is less than the saturation point $\left(Q_{\mathrm{R}(\mathrm{t})}\right)$, a direct estimation can be made using the photon flux-photosynthetic rate relationship. If $Q_{z}$ exceeds $Q_{R(t)}$, the following two-step normalization is carried out:

$$
\begin{aligned}
& \Delta Q=Q_{\mathrm{S}, 20}-Q_{\mathrm{r}, \mathrm{t}} \\
& \Delta P=P_{(20)}-\left(a_{\mathrm{P}} \cdot Q_{\mathrm{R}(\mathrm{t})}\right)\left(\mathrm{mgCmgChl}^{-1} \mathrm{~h}^{-1}\right),
\end{aligned}
$$

where $\Delta Q$ is the difference in saturation points between $20{ }^{\circ} \mathrm{C}$ and $\mathrm{t}^{\circ} \mathrm{C}, \Delta P$ is the difference between photosynthetic rates at $20{ }^{\circ} \mathrm{C}$ and at $\mathrm{t}^{\circ} \mathrm{C}$, and $a_{\mathrm{P}}$ is the linear slope of the photon flux-photosynthetic rate below the saturation point. Therefore, the photosynthetic rate above $20{ }^{\circ} \mathrm{C}$ can be obtained using the following equation:

$$
\mathrm{PPC}_{\mathrm{z}, \mathrm{t}}=P_{(20)}-\Delta P\left(\mathrm{mgCmgChl}^{-1} \mathrm{~h}^{-1}\right), t>20^{\circ} \mathrm{C}
$$

To determine the relative photosynthetic rate with respect to chlorophyll-a, $\mathrm{PPC}_{\mathrm{z}, \mathrm{t}}$ is multiplied by chlorophyll-a to calculate the unit time/water volumedependent primary production $\left(P_{\mathrm{z}}\right)$, as follows:

$$
\begin{aligned}
P_{\mathrm{z}}\left[\mathrm{mgC} \mathrm{m}^{-3} \mathrm{hr}^{-1}\right] & =\mathrm{PPC}_{(\mathrm{z}, \mathrm{t})}\left[\mathrm{mgCmgChl}^{-1} \mathrm{~h}^{-1}\right] \\
& \times \mathrm{chl}-\mathrm{a}\left[\mathrm{mgm}^{-3}\right] .
\end{aligned}
$$

The incident primary production of a water column $\left(P_{\mathrm{H}}\right)$ can be obtained from the integral of $P_{\mathrm{z}}$ at each depth and euphotic zone, as follows:

$$
P_{\mathrm{H}}\left[\mathrm{mgCm}^{-2} \mathrm{~h}^{-1}\right]=\sum_{Z=0.5}^{Z_{\mathrm{d}}} P_{\mathrm{z}}\left[\mathrm{mgCm}^{-3} \mathrm{~h}^{-1}\right],
$$

where $Z$ and $Z_{\mathrm{d}}$ are the depths of the water column. From Eq. (5), the daily primary production can be calculated from the integral of $P_{\mathrm{H}}$ during the irradiance period:

$$
\mathrm{PP}_{\text {day }}\left(\mathrm{mgCm}^{-2} \text { day }^{-1}\right)=\sum_{H=1}^{H_{\text {rad }}} \mathrm{PP}_{(\mathrm{H})}\left(\mathrm{mgCm}^{-2} \mathrm{~h}^{-1}\right) \text {. }
$$

\section{Statistical analysis}

All data were represented, and estimated PP data were analyzed using ANOVAs to characterize spatial distribution. Post hoc analyses were carried out using the Tukey test with a $95 \%$ significance level.

\section{Results and discussion}

Water temperature, salinity, and DO were represented in the range of $8.6-28.0{ }^{\circ} \mathrm{C}, 26.2-33.6 \mathrm{psu}$, and 4.9-8.9 $\mathrm{mg} \mathrm{L}^{-1}$, respectively, with no significant spatial variation within the five sampling sites (Fig. 2). The

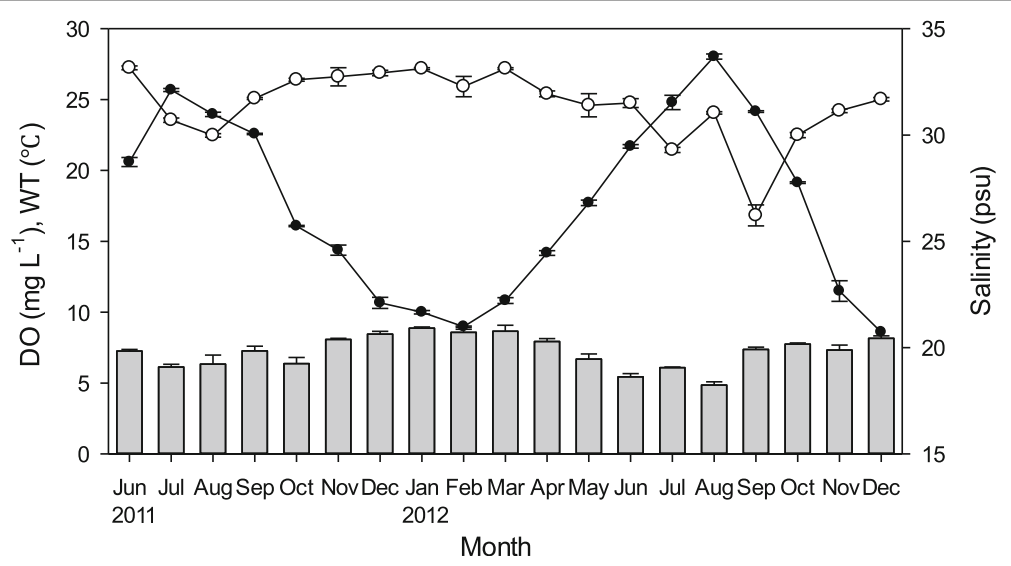

Fig. 2 Monthly variations in water temperature $(\bullet)$, salinity (o), and dissolved oxygen (vertical bars) in the waters of the study site. The reported values represent the mean and standard deviation from the five sampling stations 
maximum water temperatures in the summer off the Wando coast were low compared with those off the Tongyeong coast, which is well known for oyster culturing, and this temperature difference might be attributed to a strong tidal front around Jindo island (Jung 2001; Moon et al. 2006; Oh et al. 2008).

Precipitation can influence the success of oysters (Calvo et al. 1999; Soletchnik et al. 2007), and the input of freshwater can increase PP in coastal waters by the input of land-driven nutrient into the coastal region (Choi et al. 1997). However, no significant regression was observed between salinity and precipitation $(P>0.05)$ in the present study, which indicates that rainfall is not the main contributor of nutrients to the studied waters. The relatively consistent salinity (30-33 psu) might be influenced by the input of freshwater from adjunct land areas.

The major source of freshwater near the study site is effluent from the tidal gate at Doam-myeon, located $24 \mathrm{~km}$ north of the study area. An analysis of tidal residual flow indicates that the effluent from the tidal gate flows mainly out toward Deukryang Bay (Lee and Park 2006), which is located across the channel between Gogeum Island and Maryang-myeon in Gangjin-gun. This flow pattern of the effluent could prevent an abrupt change in salinity after a large rainfall event, which could cause a mass mortality of the rack oyster cultures. The tide with the greatest channel influence on the study area comes from the channel located between Gunwe-myeon in Wando and Pukpyeong-myeon in Haenam-gun, and this waster is weakly mixed with the tide from the Doam effluent between Goma and Sahoo Island.

No clear spatial pattern was observed in the concentration of dissolved inorganic nitrogen (DIN) and dissolved inorganic phosphate (DIP) at the sampling stations located in the seawater surrounding the oyster farm. The measured values were in the range of 0.014-0.062 mg L $\mathrm{mgr}^{-1} \mathrm{NH}_{4}-\mathrm{N}, 0.001-0.007 \mathrm{mg} \mathrm{L}^{-1}$ for $\mathrm{NO}_{2}-\mathrm{N}, \quad 0.104-0.355 \mathrm{mg} \mathrm{L}^{-1}$ for $\mathrm{NO}_{3}-\mathrm{N}$, and 0.011-0.025 $\mathrm{mg} \mathrm{L}^{-1}$ for DIP. A seasonal change was observed in nitrate, DIN, and DIP, with a slightly higher concentration in spring and summer than in winter (Fig. 3).

The nitrogen content of the water at surrounding sites was not clearly influenced by precipitation or seasonality (Table 1), which indicated that nitrogen input into this area was weak and relatively consistent. This result could be attributed to the mineralization of resuspended sediment. Resuspension of sediment can double the mineralization rates compared with sediments that are not subjected to turbulence water, regardless of turbulence interval between the events (Ståhlberg et al. 2006). The studied oyster farm is located in the intertidal zone off the Wando coast where the water depth is only 2-3 $\mathrm{m}$ at high tide. The sediment could easily be resuspended into the water column by even mild wind and the occasional passing of ships. This resuspension of the sediments might be a source of additional nutrient supply in the waters of the study area. A relatively high tidal current might also contribute to the resuspension of the sediments. The maximum tidal current in the study area is $28.1-29.1 \mathrm{~cm} \mathrm{~s}^{-1}$ during high tide (Whan et al. 2003; Cho et al. 2013b). This current, combined with increased wave action from various potential sources such as passing ships or wind (Carlin et al. 2016), could be enough to generate sediment resuspension and subsequent mineralization of the sediments.

Chlorophyll-a content in the study area ranged from 0.31 to $10.46 \mu \mathrm{g} \mathrm{L}^{-1}$, with an average mean of $2.06 \pm$ $2.10 \mu \mathrm{g} \mathrm{L}^{-1}$, and was characterized by high temporal variation but no spatial variation $(P>0.05)$. Peak phytoplankton blooms were observed in the spring and autumn of 2012. The estimated PP ranged from 17.1 to $1052.5 \mathrm{mgC} \mathrm{m}^{-2} \mathrm{day}^{-1}$, with an average of $204.2 \pm$ $224.8 \mathrm{mgC} \mathrm{m}^{-2}$ day $^{-1}$; however, with the exception of times of intense phytoplankton blooms, the PP was usually below $200 \mathrm{mgC} \mathrm{m}^{-2}$ day $^{-1}$ (Fig. 4). The trends in PP in this region are similar to those at Gosung Bay on the southern coast and Garorim Bay on the west coast of South Korea (Cho 2013). However, the estimated PP is lower than the values reported for Pukman Bay (Jeong et al. 2009), Gosueng Bay (Lee et al. 2016), HansanGeoje Bay (Park et al. 2002), and Kamak Bay (Cho et al. 1996), all oyster farming region off the southern coast of South Korea. The variations in PP in the study area are more similar to those observed off the western coast than the southern coast of South Korea. Primary production is relatively low off the southern coast of South Korea, with reported values below $200 \mathrm{mgC} \mathrm{m}$ ${ }^{-2}$ day $^{-1}$ throughout the year except during spring and autumn, when phytoplankton blooms generally occur. High turbidity, due to shallow water depth and strong tidal current, could have limited the photosynthetic efficiency of the primary producers in this region (Kuehl and Troelstrup 2013). However, during high tide, the currents could contribute an additional input of chlorophyll-a by freeing benthic diatoms from the sediment (Joint and Pomroy 1981). In the present study, microscopic examination of the phytoplankton composition indicates that benthic diatom species such as Paralia sulcata (Cho et al. 2013b) were relatively scarce. The absence of spring and autumn phytoplankton bloom has been reported to be a distinct feature of waters with high turbidity (Al-Hasan et al. 1975; Joint and Pomroy 1981; Cho 2013); however, the obvious spring and autumn blooms might be attributed to the direct or indirect influence of freshwater input from the adjacent basin and effluent from Doam-myoen at Gangjin-gun.

According to the generalized equation for photosynthesis reported by Odum (1971), the availability of 


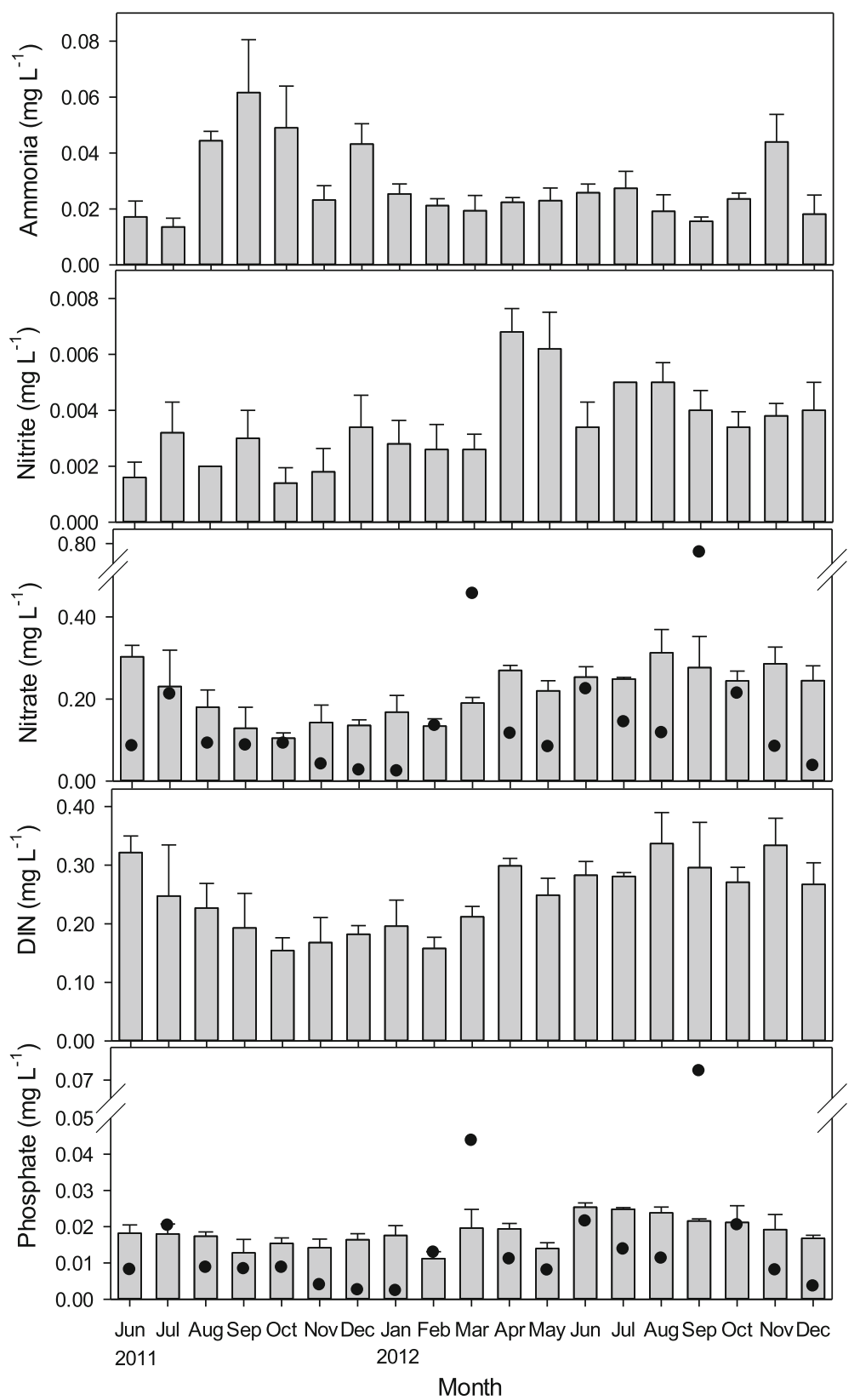

Fig. 3 Monthly variations in nutrients at the studied sites. Closed circle $(\bullet)$ indicate the estimated demand for primary production according to Odum (1971). Temporal limitations in nutrient availability were observed for both nitrate and phosphate concentrations

Table 1 Pearson correlations coefficients between water qualities

\begin{tabular}{|c|c|c|c|c|c|c|c|}
\hline & Salinity & DO & $\mathrm{NH}_{4}-\mathrm{N}$ & $\mathrm{NO}_{2}-\mathrm{N}$ & $\mathrm{NO}_{3}-\mathrm{N}$ & DIN & DIP \\
\hline$\overline{W T}$ & $-0.587^{*}$ & $-0.822^{* * *}$ & -0.0303 & 0.120 & 0.389 & 0.419 & $0.479^{*}$ \\
\hline Salinity & & 0.365 & 0.147 & -0.311 & -0.416 & -0.427 & -0.448 \\
\hline DO & & & -0.051 & -0.181 & -0.387 & -0.438 & $-0.503^{*}$ \\
\hline $\mathrm{NH}_{4}-\mathrm{N}$ & & & & -0.255 & $-0.533^{*}$ & -0.362 & -0.320 \\
\hline $\mathrm{NO} 2-\mathrm{N}$ & & & & & $0.505^{*}$ & $0.517^{*}$ & 0.323 \\
\hline NO3-N & & & & & & $0.982^{* * *}$ & $0.702^{* * *}$ \\
\hline DIN & & & & & & & $0.699^{* * *}$ \\
\hline
\end{tabular}

nitrate and phosphate for primary production was temporarily limited during the spring and autumn blooming season (Fig. 3). The nutrient availability was limited to a much greater degree in 2012 than in 2011. The hydrodynamic and geological features of this region contribute to the low availability of nutrients in these wasters. The majority of freshwater from the discharge of tidal gate was mostly flowed out toward Deukrayng Bay, meaning that most land-derived input of freshwater in this region consists of runoff, stream water, and hatchery discharge. However, the nutrient load of 


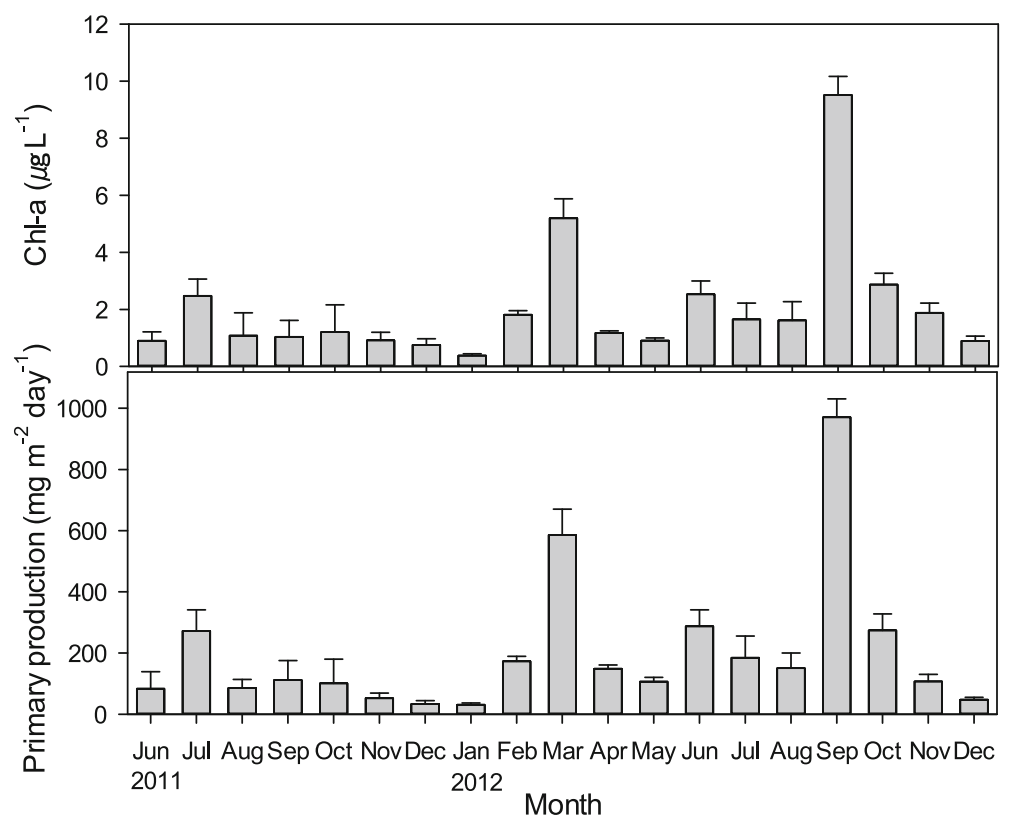

Fig. 4 Monthly variations in chlorophyll-a and primary production in the waters of the study area

adjacent basin did not significantly affect the water quality in the study area, as the pollution load showed half dilution within a radius of $300 \mathrm{~m}$ (Kang et al. 2015).

\section{Conclusion}

Despite the studied waters being located in semienclosed ria coast surrounded by several islands, hydrodynamic and geological features make the waters in this area favorable to oyster farming with relatively higher PP. Sediment resuspension might contribute nutrients input that enhance primary production, which satisfied the nutrient demand during the times when phytoplankton blooming are absent; however, during the spring and autumn when phytoplankton blooms occur, this process cannot provide sufficient nutrients for PP due to insufficient nutrient input from the adjacent basin and terrestrial sources.

\section{Abbreviations}

ANOVA: Analysis of variance; DIN: Dissolved inorganic nitrogen; DIP: Dissolved inorganic phosphorus; DO: Dissolved oxygen; MSY: Maximum sustainable yield; PP: Primary production

\section{Acknowledgements}

We wish to acknowledge the fish farmers in Yeongheung-ri Wando for allowing us to use their tidal flat farming ground and their assistance throughout the study.

\section{Funding}

This research was a part of the project titled "Development of sustainable aquaculture techniques for tidal flat oyster" funded by the Ministry of Oceans and Fisheries, Korea.

Availability of data and materials Not applicable
Authors' contributions

WGJ and SMC designed the study. WGJ carried out the model for primary production. SMC carried out the field survey and drafted the manuscript. Both authors read and approved the final manuscript.

\section{Ethics approval}

Experimental protocols followed the guidelines of the Animal Care and Use Committee of Kunsan National University.

\section{Consent for publication}

Not applicable

\section{Competing interests}

Both authors declare that they have no competing interests.

\section{Publisher's Note}

Springer Nature remains neutral with regard to jurisdictional claims in published maps and institutional affiliations.

\section{Author details}

'Department of Seafood and Aquaculture Science, Gyeongsang National University, Tongyeong 650-160, Korea. ${ }^{2}$ School of Applied Marine bioscience, Kunsan National University, Gunsan 573-701, Korea.

Received: 22 December 2017 Accepted: 26 January 2018

Published online: 06 April 2018

\section{References}

Al-Hasan RH, Coughlan SJ, Pant A, Fogg GE. Seasonal variations in phytoplankton and glycollate concentrations in the Menai Straits, Anglesey. J Mar Biol Assoc UK. 1975;55:557-65.

Calvo GW, Luckenbach MW, Allen SKA Jr, Burreson EM. Comparative field study of Crassostrea gigas (Thunberg, 1793) and Crassostrea virginica (Gmelin, 1791) in relation to salinity in Virginia. J Shell Res. 1999;18:465-73.

Carlin JA, Lee G-H, Dellapenna TM, Laverty P. Sediment resuspension by wind, waves, and currents during meteorological frontal passages in a micro-tidal lagoon. Estuar Coast Shelf S. 2016;172:24-33.

Cho E-I, Park C-K, Lee S-M. Estimation of carrying capacity in Kamak Bay (II) - estimation of carrying capacity of oyster culture ground. Korean J Fish Aquat Sci. 1996;29:709-15. 
Cho SM. Food availability of oyster farms in Woongdo, Seosan in the western coast of Korea during summer. Korean J Malacol. 2013;29:283-9.

Cho S-M, Choi MS, Jo S-G, Kim J-Y, Park K-S. Development of cultural technique for the Pacific oyster rearing at rack culture system in mudflat, Korea. Gunsan: Ministry of Oceans and Fisheries; 2013.

Choi WJ, Chun YY, Park JH, Park YC. The influence of environmental characteristics on the fatness of Pacific oyster, Crassostrea gigas, in HansanKoje Bay. J Korean Fish Soc. 1997;30:794-803.

Fisheries MOOA. Korean standard method for marine environment. Seoul: Minsitry of oceans and Fisheries; 2013.

Han HS, Cho S-M. Study on optimal condition for oyster rack culture in terms of tidal exposure and rack height in Wando coast, Korea. Korean J Malacol. 2013;29:43-50.

Jeong WG, Cho SM, Lee SJ. Studies for the sustainable management of oyster farms in Pukman Bay, Korea: estimate of primary production. Fish Aqua Sci. 2009;12:111-7.

Joint IR, Pomroy AJ. Primary production in a turbid estuary. Estuar Coast Shelf S. 1981;13:303-16.

Jung HD. On the mechanism of cold water appearance and variation of oceanographic conditions in the southwest coastal waters of Korea in summer. Busan: Pukyong University; 2001.

Kang JH, Cho S-M, Kim TO, Park KS. Sanitary assessment of the oyster rack culture waters in Wando, Korea. Korean J Malacol. 2015;31:129-36.

Kuehl LC, Troelstrup NH. Relationships between net prmary production, water transparency, chlorophyll a, and total phosphorus in Oak lake, Brookings county, South Dakota. Proc S D Acad S. 2013;92:67-78. 2013

Lee B, Kang H, Kang Y. Primary production in the oyster farming bay. Bull Korean Fish Soc. 1991;24:39-51.

Lee K. Current status and enhancement plans of porphyra cultivation industry in korea. Mokpo: Mokpo National Maritime University; 2006.

Lee MO, Park IH. Physical marine environment at the north of Wando and Gogeumdo receiving the effluents from land. J Environ Sci. 2006;15:45-58.

Lee SJ, Jeong WG, Cho SM, Kwon JN. Estimation of carrying capacity by food availability for farming oysters in Goseong Bay, Korea. Korean J Malacol. 2016; 32:83-93.

Moon SY, Jung CS, Soh HY, Oh HJ. Distribution of zooplankton communities in the coastal area of Wando in summer, Korea. J Environ Biol. 2006;24:329-36.

Newell R, Langdon CI. Mechanisms and physiology of larval and adult feeding. The eastern oyster Crassostrea virginica. Manyland: Maryland Sea Grant; 1996. p. 185-229.

Odum EP. Fundamentals of ecology. Philadelphia: Saunders; 1971.

Oh HJ, Kim SH, Moon S-Y. The characteristics of phytoplankton community of cold water in the around sea of Wando in summer, 2005. J Environ Sci. 2008;17:949-56.

Park JS, Kim HC, Choi WJ, Lee WC, Park CK. Estimating the carrying capacity of a coastal bay for oyster culture 1. Esitmating a food supply to oysters using an ecohydrodynamic model in Geoje-Hansan Bay. J Korean Fish Soc. 2002;35:395-407.

Parson T, Maita Y, Lalli C. Determination of Chlorophylls and Total Carotenoids: Spectrophotometric Method, A Manual of Chemical and Biological Methods for Seawater Analysis. Pergamon Press, Oxford; 1984.

Soletchnik P, Ropert M, Mazurié J, Gildas Fleury P, Le Coz F. Relationships between oyster mortality patterns and environmental data from monitoring databases along the coasts of France. Aquaculture. 2007;271:384-400.

Ståhlberg C, Bastviken D, Svensson BH, Rahm L. Mineralisation of organic matter in coastal sediments at different frequency and duration of resuspension. Estuar Coast Shelf S. 2006;70:317-25.

Steemann Nielsen E. Marine photosynthesis with special emphasis on the ecological aspects. Amsterdam and New York: Elsevier Science Publishing Company; 1975.

Uslu FE, Pekkan K. Mytilus galloprovincialis as a smart micro-pump. Biol Open. 2016;5:1493-9.

Whan K, Rok MS, Jung PS. Effects of Tidal Flat on Hydrodynamics. In KSCE 2003 Convention. Daegu: Korean Soceity of Civil Engineers; 2003:4965-70.

\section{Submit your next manuscript to BioMed Central and we will help you at every step:}

- We accept pre-submission inquiries

- Our selector tool helps you to find the most relevant journal

- We provide round the clock customer support

- Convenient online submission

- Thorough peer review

- Inclusion in PubMed and all major indexing services

- Maximum visibility for your research

Submit your manuscript at www.biomedcentral.com/submit
Biomed Central 